\title{
Educomunicação científica: rádio, jornalismo e popularização das ciências na construção da cidadania
}

Patrícia Maria Martins Nápolis

Doutora em Ciências pela UFSCar e docente na Universidade Federal do Piauí (Centro de Ciências da Natureza).

E-mail: pnapolis@uol.com.br

Alessandro Augusto Barros Façanha

Mestre em Educação Brasileira e docente na Universidade Federal do Rio Grande do Norte.

E-mail: afacanha@ufpi.edu.br

Jociara Pinheiro Luz

Graduanda (iniciação científica) - Universidade Federal do Piauí.

E-mail: jociara_luz@hotmail.com

Resumo: O presente trabalho tem por finalidade desvelar as conexões entre a rádio universitária e o processo de educomunicação científica. Trata-se de uma descrição analítica de um projeto educomunicador que insere a cultura científica como um caminho para a construção de conhecimento e cidadania para além do espaço universitário, tendo como foco a difusão de ciência no cotidiano das pessoas a partir de uma programação perene de divulgação de ciência, tecnologia e inovação. Como resultados preliminares, são descritos parâmetros de participação da comunidade com o projeto, bem como os desdobramentos jornalísticos e educacionais oriundos desta ação, os quais revelaram que o rádio, apesar das inúmeras possibilidades de comunicação existentes, permanece como um grande aliado no processo de difusão e construção de conhecimento, bem como uma ferramenta importante no diálogo entre o erudito e o coloquial podendo ser vastamente aproveitado nos processos educacionais.

Palavras-chave: educomunicação; divulgação científica; linguagem radiofônica; rádio.
Abstract: The paper aims to reveal the connections between college radios and the process of scientific educomunication. It analyses a educomunicational project that shows the scientific culture as a way to the construction of knowledge and citizenship beyond the university limits, focused on scientific promotion in the everyday life through a continuous agenda of science, technology and innovation. The preliminary results are the participation of the community in the project, as well as journalistic and educational projects born within this project, which revealed that the radio, despite its competitors, remains a great ally in the process of constructing and spreading knowledge. As well as an important tool in the dialog between highbrow and popular, with large potential in education.

Keywords: educommunication; science communication; radio language; radio. 
1. RUBLESCKI, Anelise. Jornalismo científico: problemas recorrentes e novas perspectivas. Ponto de Acesso, v. 3, n. 3 , pp. 407-427, 2009; MASSARANI, Luisa, BAUER, Martin W., e AMORIM, Luís. Um raio $X$ dos jornalistas de ciência: há uma nova "onda" no jornalismo científico no Brasil? Comunicação \& Sociedade, v. 35, n. 1, pp. 111-129, 2013; MASSARANI, Luisa, e MERZAGORA, Matteo. Socially inclusive science communication. JCOM: Journal of Science Communication, v. 13, n. 2, 2014

2. MASSARANI, Luisa et al. A divulgação científica no Brasil e suas origens históricas. Tempo Brasileiro, v. 188, 2012, pp. 5-26.

3. BUENO, Wilson da Costa. Os novos desafios do jornalismo científico. In: VII Congresso Iberoamericano de Jornalismo Científico. Argentina, 2001.

4. MASSARANI, Luisa; BUYS, Bruno. A ciência em jornais de nove países da América Latina. Los desafíos y la evaluación del periodismo científico en Iberoamérica: Jornadas Iberoaméricanas sobre la Ciencia en los medios masivos. Madrid: Cyted, 2008, pp. 19-35.

5. ZAMBONI, Lilian Márcia Simões. Cientistas, jornalistas e a divulgação científica: subjetividade e heterogeneidade no discurso da divulgação científica. Forward Movement, 2001.

\section{DIVULGAÇÃO CIENTÍFICA: PERCURSOS E PROPOSTAS}

A divulgação científica consiste em uma área da Comunicação voltada a divulgar informações sobre a amplitude de ciência, tecnologia, inovação e conhecimento científico com intuito de difundir informações relevantes no percurso de seus desenvolvimentos, aplicações e atualidades que aproximem o cidadão a esses contextos. Ao longo do tempo, atendeu a interesses e motivações diversificados, os quais, correlacionados ao contexto histórico, denotam essas variações em decorrência dos pressupostos e paradigmas vigentes na ciência, na cultura e nos meios de comunicação de cada época ${ }^{1}$.

No Brasil, apesar da ausência de um consenso em relação ao desenvolvimento e percurso histórico das atividades próprias de divulgação científica, há marcos e cronologias consideradas relevantes a produção e difusão desse conhecimento. Ressaltam-se a transferência da corte portuguesa no início do século XIX, o desenvolvimento de círculos de intelectuais e cientistas no fim século XIX, a participação das universidades e das instituições ligadas à ciência no início do século XX e a incidência do conhecimento científico em setores específicos do jornalismo ${ }^{2}$.

Nesse âmbito, merece destaque o chamado jornalismo científico que voltado à divulgação de informações e notícias sobre ciências, teve como marco precursor as matérias difundidas em seções específicas de jornais impressos e revistas especializadas em temáticas como agricultura e pecuária. Um exemplo desse campo jornalístico foi o jornal O Correio Braziliense que contemplava, desde sua fundação, cadernos temáticos e seções especializadas, que traziam desde assuntos ligados a agropecuária, desenvolvimento mineral e geografia, matérias sobre manejo biotecnológico e questões específicas à ciência. Porém, como toda iniciativa precursora, de maneira ainda incipiente ${ }^{3}$.

Com o passar dos anos, em virtude do aumento do interesse da população por temas de ciência e tecnologia e em decorrência do incremento da produção científica e sua influência no cotidiano das pessoas, supera-se a fase preliminar de difusão científica e se inaugura o período de amadurecimento e consolidação da divulgação científica brasileira com a intensa produção de conhecimento e sua ampla veiculação como uma forma consolidada de comunicação. Destacam-se as atividades de ciência e tecnologia promovidas pela Sociedade Brasileira para o Progresso da Ciência (SBPC), a editoração de periódicos de ciências mais voltados para a comunidade acadêmica e revistas especializadas em divulgação científica para o público em geral que passam a incorporar esses conceitos ${ }^{4}$.

Ressalta-se no período, sobretudo a partir dos anos de 1980, tanto em função da crescente demanda de interesse como amparado pelo crescimento desses setores específicos de pesquisas, o surgimento dos eventos de divulgação científica, espaços de ciências e criação de revistas como a Ciência Hoje, em 1982, a Ciência Hoje das Crianças, em 1986, e o Jornal da Ciência, em 19925.

Em consonância a essas ações, o conceito da divulgação científica evolui para além do campo da Comunicação e do jornalismo elevando à divulgação 
das ciências a um campo do conhecimento e sua difusão a um processo peculiar de democratização e cidadania. Na mídia escrita e no telejornalismo, há importante veiculação com destaque para os projetos específicos de divulgação científica desenvolvidos nas TVs educativas como o Projeto Ver Ciência e TV é Ciência ${ }^{6}$.

Consolida-se uma fase de difusão mais perene que amplia a compreensão de conceitos científicos, pesquisas em ciência e tecnologia, inovação e informações do cotidiano. Inicia-se uma fase de medição comunicativa que atua como elo de comunicação e produção de conhecimento conferindo à divulgação científica uma ponte entre a comunidade científica e a sociedade em geral ${ }^{7}$.

Atrelar informação e conhecimento científico na perspectiva da informalidade do discurso torna a ciência acessível, e por meio de um processo de educomunicação científica promove cidadania e protagonismo social, pois revela conteúdos de relevância para o cotidiano em uma comunicação acessível e promotora do direito à informação, garantindo inserção, informação e cidadania. Dessa maneira, o processo de divulgação científica ganha status diferenciado na vida das pessoas interferindo no dia a dia, nos seus hábitos, rotinas e, sobretudo, no modo de vida, de pensar e de agir.

[...] a mídia, hoje, coloca a agenda de discussão. Isto é, segundo pesquisas, ao redor de $82 \%$ dos temas e assuntos que são falados no trânsito, no trabalho, em casa, nos encontros sociais etc. são colocados à discussão pela mídia; ela determina, até certo ponto, o que deve ser falado e discutido ${ }^{8}$.

Nesse sentido, a difusão de ciências e seu processo de divulgação amplia o conceito de comunicação adquirindo uma denominação educomunicativa, de forma que, para além do aspecto da informação, amplia o espectro da comunicação e cria ecossistemas de comunicativos e educativos que possibilitam o crescimento e desenvolvimento dos indivíduos e da coletividade.

\section{A EDUCOMUNICAÇÃO CIENTÍFICA NO CONTEXTO DO RÁDIO}

No ambiente atual da midiatização e tecnologização da informação o rádio expandiu o dial e passou a ter outra possibilidade a partir da incorporação de um sistema dialético de informação que demarca novos locais e hibridizações a partir de novos nexos, bricolagens e aperfeiçoamento da linguagem e da difusão ${ }^{9}$.

Sai de cena o rádio convencional e entra a radiofusão interconectada à web, redes sociais e novos espaços de comunicação. Nesse contexto, atribui-se a compatibilização das frequências com as páginas da internet e o protagonismo dos ouvintes, os quais, interagem, opinam e constroem possibilidade de pautas ${ }^{10}$.

Nesse âmbito, ganham força as rádios comunitárias e as rádios institucionais de ensino, como as rádios universitárias, pois consistem em instituições de caráter público e laboratorial, que, a partir dessa perspectiva, devem oferecer uma produção que cubra a maior parte dos setores da população. Isso não
6. MASSARINI, Luisa et al, op. cit., 2012; RIOS, Aline de Oliveira et al. Jornalismo científico: o compromisso de divulgar ciência à sociedade - a comunicação entre jornalistas e pesquisadores e a responsabilidade social na disseminação de informações científicas. Publicatio UEPG: Ciências Sociais Aplicadas, v. 13, n. 2, 2009.

7. RUBLESCKI, op. cit.

8. GUARESCHI, Pedrinho A. Mídia e cidadania. Conexão-Comunicação e Cultura, v. 5, n. 9, 2010, p. 31.

9. DEL BIANCO, Nelia R. O rádio brasileiro na era da convergência. São Paulo: Intercom, 2012.

10. MIRANDA, Mozarth Dias de Almeida. A pauta jornalística na convergência digital: outros caminhos e novos desafios. Dissertação de mestrado. Universidade Estadual Paulista. Faculdade de Arquitetura, Artes e Comunicação, Bauru, 2011. 
11. DEUS, Sandra de Fatima Batista de. Rádios Universitárias Públicas: compromisso com a sociedade e com a informação. Em Questão: revista da Faculdade de Biblioteconomia e Comunicação da UFRGS. Porto Alegre, v. 9, n. 2, jul./dez. 2003, pp. 327-338.

12. Este era o número de rádios universitárias na ocasião da pesquisa mencionada, desconsiderando as rádios vinculadas às instituições privadas. Hoje, de acordo com dados da Intercom, considerando as instituições públicas e privadas, existem 56 rádios universitárias no Brasil. Disponúvel em: <www. portalintercom.org.br/a-intercom>. Acesso em:

8 nov. 2016

13. LOPES, Cristiano Aguiar. Regulação da radiodifusão educativa. Consultoria Legislativa, 2011

14. ZUCULOTO, Valci Regina Mousquer. A construção histórica da programação de rádios públicas brasileiras. Tese de doutorado. Faculdade de Comunicação Social, Pontifícia Universidade Católica do Rio Grande do Sul, Porto Alegre, 2010.

15. FERRARETTO, Luiz Artur; KLÖCKNER, Luciano. E o rádio?: novos horizontes midiáticos. Porto Alegre: EDIPUCRS, 2010.

16. MANNHEIM, Karl. Ideology and Utopia. Routledge: Harvest Books 2013. significa somente que devem atingir o maior número de ouvintes, mas oferecer uma programação que corresponda aos interesses de diferentes setores da população ${ }^{11}$.

Esses veículos estão imbuídos do papel educativo para além de uma visão comercial e de mercado típico das rádios convencionais: objetivam aliar qualidade, informação e cidadania, agregando em suas programações, arte, cultura e entretenimento, porém, com uma missão de aliar ações de ensino, pesquisa e extensão próprias das instituições de ensino superior.

No caso brasileiro, existem 38 emissoras de rádio ${ }^{12}$ associadas a universidades públicas - federais, estduais ou municipais. Além dessas, existem também outras rádios universitárias ligadas a instituições privadas, reguladas pela Empresa Brasileira de Comunicação (EBC) e reguladas pelo decreto n. 5.396, de 21 de março de 2005, dispõe sobre a veiculação de conteúdo e repasse de recursos em emissoras de radiodifusão educativa ${ }^{13}$.

Em conformidade com as propostas referentes à natureza de suas existências, as rádios universitárias ampliam o escopo das rádios públicas brasileiras com caráter eminentemente cultural, educativo e de formação, executando projetos educacionais e culturais de importância para a construção cidadã, os quais:

aprofundam o desenvolvimento de um modelo educativo-cultural que analisamos como baseados em concepções ampliadas do que é educar e transmitir cultura pelo rádio: mesclam programas musicais, artísticos-culturais, educativos não formais e formais, estes do mesmo modo que as rádios-escolas. Isto é, buscam educar com aulas, mas também com programação musical, artística, informativa/jornalística e até de entretenimento ${ }^{14}$.

Nesse sentido, a população em geral encontra nas rádios universitárias um local de amplificação do pensamento acadêmico, porém decodificado em um formato acessível com uma linguagem do cotidiano onde é possível se estabelecer um sítio de educomunicação permanente. O objeto deste estudo é um projeto desenvolvido no âmbito da extensão universitária para produzir e difundir ciência, tecnologia e inovação por meio de educomunicação na rádio universitária da Universidade Federal do Piauí.

\section{UMA PROPOSTA DE EDUCOMUNICAÇÃO CIENTÍFICA E CIDADANIA}

Um processo radiodifusor inserido na proposta educativa consiste em uma ferramenta midiática promotora de conhecimento, para além da proposta midiática, pois encerra as qualidades educomunicativas que visam, não somente a informação, mas também a criação de espaços de desenvolvimento coletivo promotores de educação e cidadania ${ }^{15}$.

Nesse contexto, surge o objeto em análise, que consiste em um projeto de educomunicação científica, o qual, segundo um olhar sociológico, circunscreve uma proposta de organização social capaz de potencializar intenções 
realizáveis em uma perspectiva de transformação utópica ${ }^{16}$, pois delibera uma ação precursora em seu tempo/espaço p ois contempla uma proposta de educomunicação científica até então incipiente no âmbito da FM/UFPI.

Enquanto objetivo central e concepção ideológica, o projeto insere a cultura científica como um caminho para a construção de conhecimento e cidadania para além do espaço universitário e tendo como foco a difusão de ciência no cotidiano das pessoas a partir de uma programação perene de divulgação de ciência, tecnologia e inovação.

Institucionalmente, o projeto Educando Com(ns)Ciências surge em resposta ao Edital Proext/SeSU/MEC de 2014, na área temática da Comunicação, sendo encaminhado para concorrência nacional do referido edital via Sistema de Informação e Gestão de Projetos do Ministério da Educação (http:// sigproj1.mec.gov.br) e contemplado com recursos para execução no período de janeiro a dezembro de 2014.

A ideia do programa, apesar de ousada para a realidade da rádio e para o município de Teresina até então, pois não havia nada nos meios de comunicação que contemplasse a temática da divulgação científica, constituía-se viável dada a tradição educativa da Universidade Federal do Piauí em relação ao seu modelo extensionista.

Norteado pelas demandas sociais e pela vanguarda de unir ciência e jornalismo em uma mesma cena - a rádio - e inserido em um ambiente de inquietações, provocações, debates e promoção de cidadania, tem origem um projeto de educomunicação científica que, como o nome sugere, imbuído no processo de reflexão/conscientização da população sobre seu papel social frentes as demandas do cotidiano.

Quanto às temáticas, foram produzidas séries de programas a partir de temas geradores delimitados com a dinâmica social local e atrelados aos conteúdos transversais dos parâmetros curriculares do ensino de ciências da natureza. Durante a fase de execução do programa via Edital PROEXT/ MEC 2014, foram produzidos e executados programas semanais envolvendo sustentabilidade, diversidade, cultura, saúde e meio ambiente. Compondo o rol de entrevistados, gestores públicos, pesquisadores, professores e pessoas da comunidade envolvidos em projetos sociais afins com as temáticas, além de artistas que representassem a cena artístico-literária local.

A partir de um modelo de mesas redondas e debates-entrevistas, formatou-se a proposta de um programa semanal de radiofusão com mediação do jornalismo, por meio da participação/produção dos bolsistas de Comunicação Social, integrado ao olhar do cientista, representado pelo coordenador da proposta e por bolsistas do curso de Ciências da Natureza da Universidade Federal do Piauí. Nessa perspectiva, ao contrário do formato habitual, no qual a mídia discute e apresenta ciências sob o olhar exclusivo do comunicador, o projeto aliou ciência e comunicação em um mesmo ambiente. 
17 Considera-se como conceito de pauta o adotado por Lage (2013), segundo o qual, consiste na atividade jornalística de delimitação, elaboração e construção da temática a ser investigada para ser noticiada no meio de comunicação.

18 CANAVILHAS, João. Do gatekeeping ao gatewatcher: o papel das redes sociais no ecossistema mediático. II Congresso Internacional de Comunicación. 2010.

19 FERRARETTO, Luiz Artur, KLÖCKNER, Luciano, op. cit., 2010.

20 Idem, ibidem.

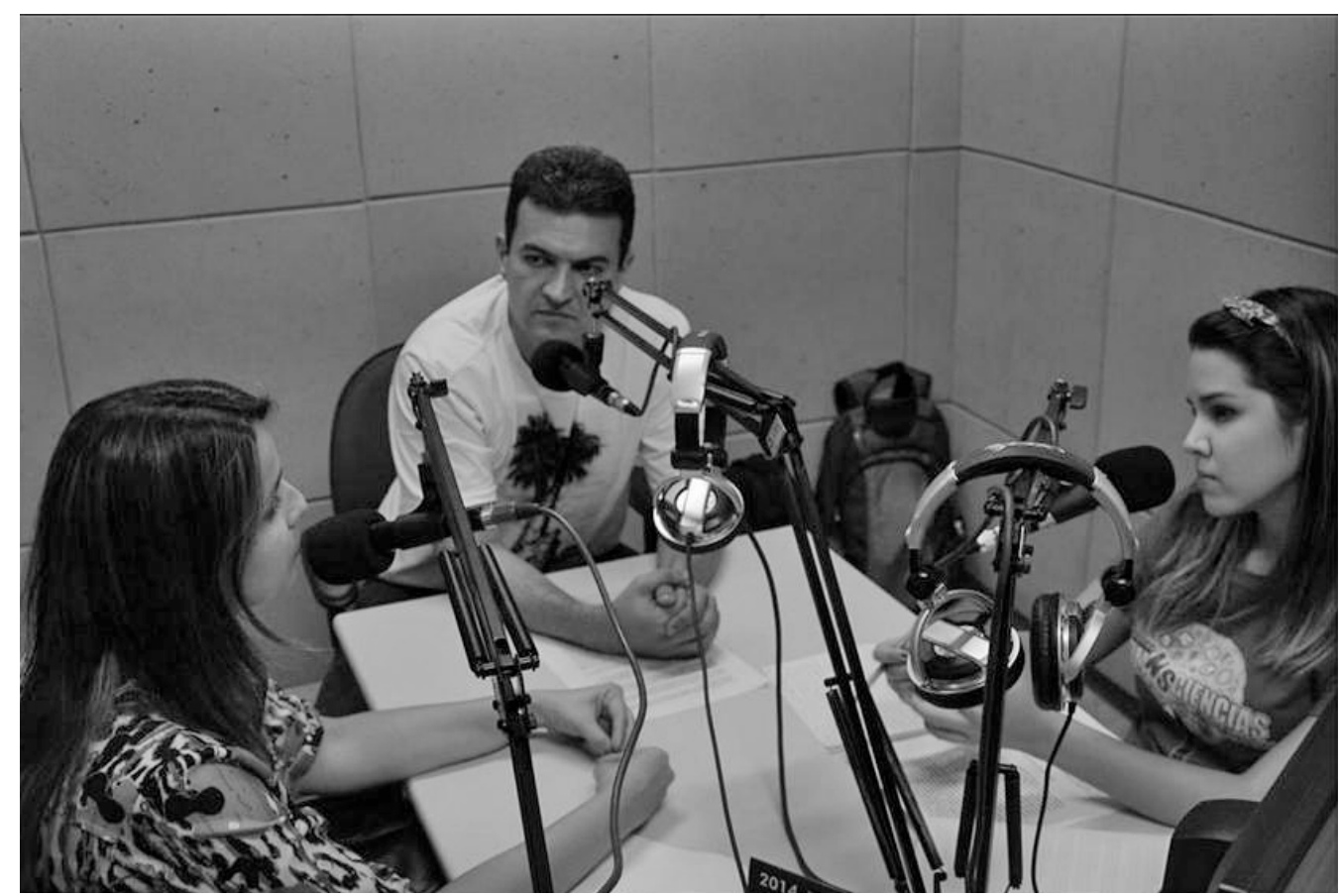

Figura 1: ambiente do estúdio durante execução do programa ao vivo.

\section{UM PROJETO EDUCOMUNICADOR E PROMOTOR DE CIDADANIA: A INTERFACE MIDIÁTICA DAS AÇÕES}

Pautado na multimodalidade midiática, optou-se pela incorporação de diversas mídias e modalidades de comunicação, tanto na divulgação/veiculação do programa, quanto na produção/edição das pautas ${ }^{17}$, a partir da participação do ouvinte. Dessa forma, incorporou-se à plataforma radiofônica uma página oficial no Facebook, Twitter, Instagram, além da veiculação em tempo real do programa na internet, por meio da página <www.fmufpi.net>, na qual o ouvinte acompanhou a programação para além da sintonia de rádio convencional.

Tais estratégias permitem uma interação maior e imediata, pois funcionam como uma transição de funções, as quais, o papel de editor (gatekeeping) e do receptor (gatewatching), se interseccionam à medida que o ouvinte ou espectador protagoniza ações e realiza um papel midiático protagonista ${ }^{18}$.

A convergência de mídias constitui-se como modelo de hibridação comunicativo que permite uma pluralidade de diálogos e interseções culturais, históricas e sociais, pois mistura bases analógicas, digitais, radiofônicas e virtuais em uma simbiose comunicativa e construtora da informação e do conhecimento.

Os processos de hibridação - ou seja, a possibilidade de mistura de um meio em outro, de uma visualidade em outra - se intensificam a partir do digital e vão transformar radicalmente outras duas categorias da visualidade: a temporalidade e a espacialidade. Mais do que uma simples "colagem" de meios, a hibridação tem profundas consequências culturais ${ }^{20}$. 
Educomunicação científica - P. M. M. Nápolis, A. A. B. Façanha e J. P. Luz

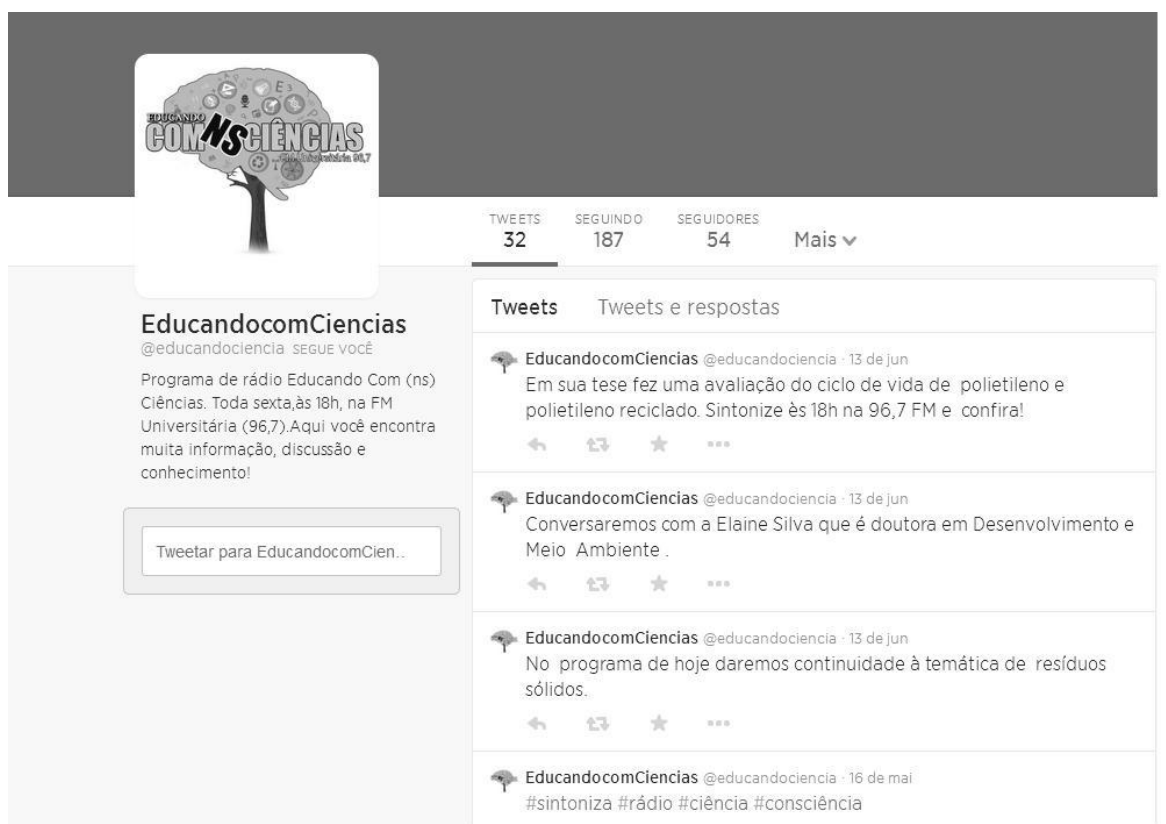

Figura 2: layout do programa nas redes sociais - Twitter.

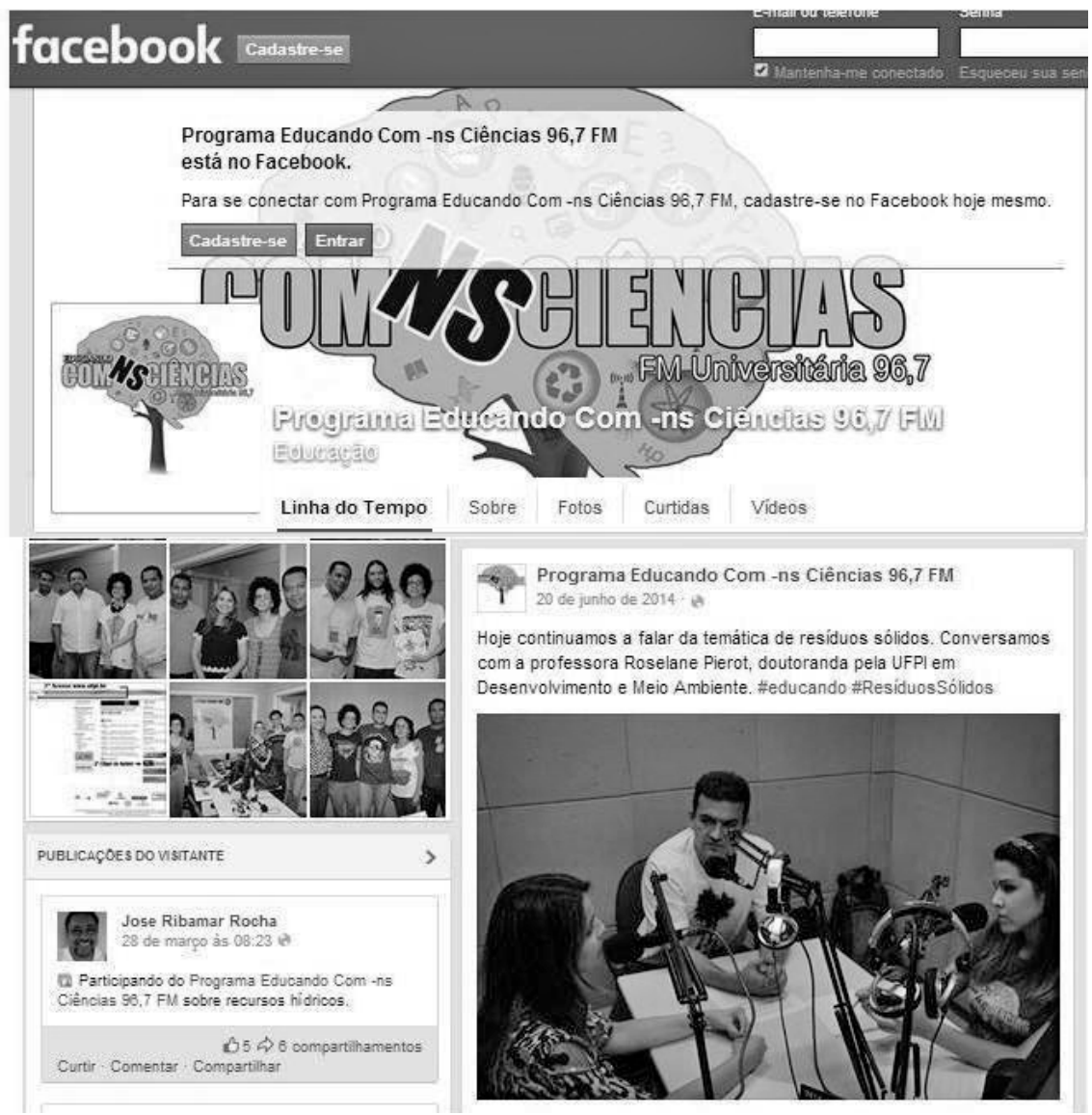

Figura 2: layout do programa nas redes sociais - Facebook. 
Dessa maneira, trazer essa perspectiva para o interior da rádio universitária e para um projeto de natureza plural dada sua interdisciplinaridade e objetivos extensionistas, possibilitou múltiplos olhares e diálogos na construção de um processo educomunicador tanto para a comunidade externa à academia, como para o próprio público universitário, que viu na proposta uma forma de debater suas questões específicas de ensino, de pesquisa e de formação em geral.

Possibilitou, portanto, no âmbito institucional, a ampliação da interdisciplinaridade interdepartamental, promoção de elos entre extensão e pesquisa, extensão e ensino, além de possibilitar o acompanhamento da proposta no âmbito de sua execução, produção e prestação de contas entre a rádio e a administração superior da universidade contribuindo para a transparência das ações e do bom uso dos fomentos consignados.

\section{PERCURSO METODOLÓGICO}

A execução do programa baseou-se na perspectiva dialógica de Freire, e no conceito de ecossistema comunicativo de Martín-Barbero, visto que se interseccionam na perspectiva do diálogo cultural e da observância do respeito das singularidades dos sujeitos de forma que:

o conceito de ecossistema comunicativo, não apenas conformado pelas tecnologias e meios de comunicação, mas também pela trama de configurações constituída pelo conjunto de linguagens, representações e narrativas que penetra na vida cotidiana de modo transversal ${ }^{21}$.

O educador já não é mais o que apenas educa, mas o que enquanto educa, é educado, em diálogo com o educando que, ao ser educado, também educa. [...] Os homens se educam em comunhão, mediatizados pelo mundo. A educação é comunicação, é diálogo, na medida em que não é a transferência de saber, mas um encontro de sujeitos interlocutores que buscam a significação dos significados ${ }^{22}$."

Dessa forma, pormeio dessas concepções, foram realizados 36 programas envolvendo séries temáticas que foram escolhidas a partir das reuniões de pauta da equipe e tendo como balizador as postagens e participações dos ouvintes na página do programa na rede social do Facebook (www.facebook.com/ educandocomnsciencias?_rdr=p), as quais foram divididas em quatro eixos norteadores: educação ambiental, diversidade de gênero, promoção de saúde e sustentabilidade.

Para dar respaldo técnico-científico aos debates foram convidados, ao

21 MARTÍN-BARBERO, Jesús. Desafios culturais da comunicação à educação.Comunicação \& Educação, v. 6, n. 18 2007.

22 FREIRE, Paulo. Comunicação ou extensão. Rio de Janeiro: Editora Paz e Terra, v. 7, 1992. ngo desses programas, pesquisadores de pós-graduação, professores das áreas debatidas, estudantes de iniciação científica, gestores públicos, secretários de governo, integrantes de movimentos sociais e artistas locais que em alguns programas faziam inserções culturais diversas.

Os programas foram ao ar ao vivo, sem edições, e com a participação efetiva dos bolsistas e dos ouvintes. A cada desfecho das séries era realizado 
um programa de fechamento das temáticas com um debate entre os próprios membros da equipe e com a participação dos ouvintes.

Em relação ao modelo de produção e execução, as pautas eram feitas pelos integrantes da equipe a partir de uma temática escolhida, na qual a equipe técnica de jornalismo realizava a produção e contatos dos entrevistados. Em seguida, fazia-se uma reunião para elencar os conceitos-chave do assunto e a partir de uma pesquisa de atualização se contextualizava com as dinâmicas sociais do assunto em nível local e global.

\section{RESULTADOS PRELIMINARES: AÇÕES, CONTRIBUIÇÕES E DESDOBRAMENTOS}

O projeto em si alinha a condição programa informativo/educativo que aliou o debate social, as problemáticas contemporâneas e a interação com o público, na perspectiva da crítica, reflexão e conhecimento científico, com uma linguagem acessível e decodificadora do universo da ciência. Na condição de veículo de comunicação comunitária, contribuiu para a aproximação entre a comunidade e o poder público ${ }^{23}$ à medida que amplificou uma voz usualmente pouco ouvida: a da população ${ }^{24}$.

Ainda nesse sentido, possibilitou vozes e ecos de identidade a medida que trouxe ações discentes para a configuração da programação, conferindo espaço, oportunidades e autonomia de elaboração, construção e produção aos bolsistas, técnicos da rádio e aos cidadãos da comunidade para trabalharem em equipe.

No âmbito dos produtos acadêmicos gerados, foram confeccionados cerca de 600 CDs de áudio com as séries dos programas veiculados, distribuídos nas escolas conveniadas aos programas de iniciação à docência e aos projetos de formação de professores.

Quanto aos desdobramentos, pode-se inferir que possibilitou, no âmbito da formação inicial, um novo campo de Jornalismo dentro da UFPI e um ambiente informal de educação continuada para os alunos das Ciências Naturais, de modo que possibilitou e conferiu espaço de formação interdisciplinar.

Com relação à participação do público externo, ou seja, a comunidade de uma forma geral, observou-se intensa participação nas páginas oficiais do programa, via "curtidas" e "comentários", totalizando mais de 400 inserções até o momento da pesquisa, bem como picos de participação dos internautas no horário da programação e até duas horas depois, servindo de referencial de audiência, bem como a efetiva participação de feedback e de solicitações de pauta.

No âmbito institucional, apresentou ao departamento de Comunicação Social da UFPI uma nova forma de fazer jornalismo, dentro e fora da universidade, bem como apresentou aos jornalistas em formação, cujo currículo não vislumbra tais questões, conhecimento sobre questões científicas, as quais, dentro de suas participações, foram adequadas para a linguagem jornalística a fim de transmitir à sociedade de forma clara e direta os conceitos inerentes às ciências.
23. SCHAUN, Ângela. Educomunicação: Reflexões e Princípios. Rio de Janeiro: Mauad, 2002.

24. Um dos diferenciais promovidos pelo projeto foi o de levar as demandas da população às pautas do radiojornalismo da FM UFPI, além disso, promover a participação direta do cidadão na programação através da linha telefônica aberta durante o programa, gravações externas que eram veiculadas em forma de quadros e inseridas nos debates com os entrevistados, além da participação de agentes públicos e pessoas ligadas aos movimentos sociais em temáticas específicas do programa. 
Como diferencial para a formação de professores de ciências, contribuiu para uma nova visão dos futuros educadores, sobretudo no que tange à crítica aos modelos tradicionais, uma vez que quebra a vigência de um racionalismo técnico na abordagem dos conceitos científicos ${ }^{25}$.

\section{7. À GUISA DE CONCLUSÃO}

Não se pretende traçar conclusões finalizadas de um projeto que ainda está em curso, porém, mesmo que preliminares, as impressões e os resultados obtidos merecem destaque e considerações. Em função das premissas iniciais sob as quais a intenção de popularizar ciências e construir espaço de cidadania se ressalta: os resultados de participação da comunidade por meio do acesso às redes sociais, construção conjunta de pautas, picos de acesso por meio telefônico e do perfil do programa na internet, além da ação conjunta com escolas do município de Teresina, as quais utilizaram as mídias durante as aulas de ciências elevando a participação dos alunos e reduzindo o absenteísmo escolar.

Do ponto de vista acadêmico, promoveu ações interdisciplinares entre os cursos de jornalismo e ciências da natureza além de possibilitar três trabalhos de conclusão de curso, sendo um na área da Comunicação Social e dois na área da docência em Ciências no curso de licenciatura.

Quanto ao aspecto da cidadania, ressalta-se o pioneirismo da ação que traz vanguarda no âmbito da divulgação científica fora do eixo sul/sudeste do país contribuindo para a inserção de temáticas importantes para a construção e promoção de conhecimento.

Assim, no sentido de uma conjectura apresenta-se como virtuoso este primeiro ciclo do programa em função de seu caráter precursor e por encetar junto à comunidade e ao radiojornalismo universitário piauiense uma proposta que pode perenizar e elevar o perfil difusor de ciências local.

\section{REFERÊNCIAS BIBLIOGRÁFICAS}

BUENO, Wilson da Costa. Os novos desafios do jornalismo científico. In: Vii Congresso Iberoamericano de Jornalismo Científico. Argentina, 2001.

DE OLIVEIRA, Fabíola. Jornalismo científico. São Paulo: Editora Contexto, 2006.

CANAVILHAS, João. Do gatekeeping ao gatewatcher: o papel das redes

25. DE CARVALHO, Anna M. Pessoa; PÉREZ, Daniel Gil. Formação de professores de ciências: tendências e inovações. São Paulo: Cortez, 2012. sociais no ecossistema mediático. Trabalho apresentado no II Congresso Internacional de Comunicación. 2010.

DE CARVAlHO, Anna M. Pessoa; PÉREZ, Daniel Gil. Formação de professores de ciências: tendências e inovações. São Paulo: Cortez, 2012. 
DEL BIANCO, Nelia R. O rádio brasileiro na era da convergência. São Paulo, Intercom, 2012.

DEUS, Sandra de Fatima Batista de. Rádios Universitárias Públicas: compromisso com a sociedade e com a informação. Em Questão: revista da Faculdade de Biblioteconomia e Comunicação da UFRGS. Porto Alegre, v. 9, n. 2, jul./dez. 2003.

DE ARAUJO SOUSA, Roberto; DE CARVALHO LOPES, Paulo Fernando. Processo de implantação da Rádio Universitária da Universidade Federal do Piauí. Intercom - Sociedade Brasileira de Estudos Interdisciplinares da Comunicação XVI Congresso de Ciências da Comunicação na Região Nordeste - João Pessoa - PB - 15 a 17/05/2014.

FERRARETTO, Luiz Artur; KLÖCKNER, Luciano. E o rádio?: novos horizontes midiáticos. Porto Alegre: EDIPUCRS, 2010.

FREIRE, Paulo. Comunicação ou extensão. Rio de Janeiro: Editora Paz e Terra, v. 7, 1992.

GUARESCHI, Pedrinho A. Mídia e cidadania. Conexão-Comunicação e Cultura, v. 5, n. 9, 2010.

LAGE, Nilson. Conceitos de jornalismo e papéis sociais atribuídos aos jornalistas. Pauta Geral-Estudos em Jornalismo, v. 1, n. 1, 2013.

LOPES, Cristiano Aguiar. Regulação da radiodifusão educativa. Consultoria Legislativa, 2011.

MANNHEIM, Karl. Ideology and Utopia. Routledge: Harvest Books, 2013.

MARTÍN-BARBERO, Jesús. Desafios culturais da comunicação à educação. Comunicação \& Educação, v. 6, n. 18, 2007.

MASSARANI, Luisa et al. A divulgação científica no Brasil e suas origens históricas. Tempo Brasileiro. v. 188, 2012.

; BUYS, Bruno. A ciência em jornais de nove países da América Latina. Los desafíos y la evaluación del periodismo científico en Iberoamérica: Jornadas Iberoaméricanas sobre la Ciencia en los medios masivos. Madrid: Cyted, 2008.

; BAUER, Martin W., e AMORIM, Luís. Um raio X dos jornalistas de ciência: há uma nova "onda" no jornalismo científico no Brasil? Comunicação \& Sociedade, v. 35, n. 1, 2013.

_; MERZAGORA, Matteo. Socially Inclusive Science Communication. JCOM: Journal of Science Communication, v. 13, n. 2, 2014. MIRANDA, Mozarth Dias de Almeida. A pauta jornalística na convergência digital: outros caminhos e novos desafios. 2011. 
RIOS, Aline de Oliveira et al. Jornalismo científico: o compromisso de divulgar ciência à sociedade-a comunicação entre jornalistas e pesquisadores e a responsabilidade social na disseminação de informações científicas. Publicatio UEPG: Ciências Sociais Aplicadas, v. 13, n. 2, 2009.

RUBLESCKI, Anelise. Jornalismo científico: problemas recorrentes e novas perspectivas. Ponto de acesso, v. 3, n. 3, p. 407-427, 2009.

SCHAUN, Ângela. Educomunicação: Reflexões e Princípios. Rio de Janeiro: Mauad, 2002.

ZAMBONI, Lilian Márcia Simões. Cientistas, jornalistas e a divulgação científica: subjetividade e heterogeneidade no discurso da divulgação científica. Forward Movement, 2001.

ZUCULOTO, Valci Regina Mousquer. A Construção histórica da programação de rádios públicas brasileiras. Tese de doutorada. Faculdade de Comunicação Social da PUC-RS. Porto Alegre, 2010. 